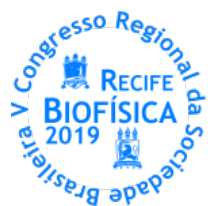

\title{
ADENOSINA, POSSÍVEL AGENTE PROLIFERATIVO EM CULTURA DE CARDIOMIÓCITOS NEONATAIS DE RATO
}

\author{
Matheus Fabião de Lima ${ }^{1 *}$, Enéas Ricardo de Morais Gomes² \\ ${ }^{1}$ Laboratório de Biotecnologia Celular e Molecular, UFPB; ${ }^{2}$ Laboratório de Biotecnologia Celular e Molecular, UFPB \\ *matheusdn2@hotmail.com
}

\section{RESUMO}

Introdução: As doenças cardiovasculares (DCVs) configuram um grave problema de saúde pública ao redor do mundo, pois se refletem como a maior causa de mortes acarretadas por doença, além de serem apresentadas como um dos maiores gastos com saúde na maioria dos continentes. Isso se deve, majoritariamente por uma das consequências mais fatais, acarretadas pelas DCVs, o infarto agudo do miocárdio. Esse que, quando não acarreta a morte do indivíduo contribui para a diminuição gradativa da qualidade de vida do mesmo, contribuindo para uma fatalidade posterior. As terapias empregadas no pós-infarto, tem se mostrado insuficientes, do ponto de vista de cura, o que tem levado os pesquisadores a buscar novas alternativas efetivas para o tratamento desse quadro patológico. Considerando dados da literatura, demonstrando que a ativação do receptor $A_{2 A}$ de adenosina estimula a proliferação de diferentes tipos celulares, o presente trabalho tem como objetivo investigar a ação proliferativa, induzida pela adenosina, em cardiomiócitos isolados. Materiais E Métodos: Para isso, foi feito a cultura primária de cardiomiócitos neonatais de rato, que após períodos variados de incubação com adenosina, foram submetidos a ensaio de viabilidade por vermelho neutro, ensaio de proliferação e viabilidade por cristal violeta, ensaio de viabilidade metabólica e proliferação por redução do 3-(4,5-dimethylthiazol-2-yl) -2,5diphenyltetrazolium bromide - MTT, ensaio semi-quantitativo de proteínas totais e ensaio de contagem de núcleos, objetivando a detecção de proliferação celular. Resultados E Discussão: Pôde-se mensurar um aumento na absorbância, no ensaio de vermelho neutro de $59 \%$, comparado com o controle, para o melhor efeito observado, aumento de 47\%, na absorbância no ensaio de cristal violeta em comparação com o controle; o ensaio de MTT, embora tenha mostrado que a adenosina não influencia no metabolismo dos cardiomiócitos, não apresentou um aumento na absorbância, como visto em outros ensaios; a semi-quantificação de proteínas totais demonstrou um aumento de 59\% na absorbância, em comparação com o controle, e a contagem de núcleos apresento um aumento de $29 \%$ na quantidade de núcleos, em comparação com o grupo. Os resultados se mostraram interessantes, uma vez que ao primeiro momento, demonstraram um aumento na quantidade de proteínas totais, aumento na quantidade de lisossomos, aumento na quantidade de células por marcação com cristal violeta e por contagem de núcleos, no entanto em algumas repetições esses resultados não se repetiram ou não foram significativamente estatísticos. Conclusões: Postulamos que a adenosina poderia estar influenciando na taxa de proliferação de cardiomiócitos por demonstrar indícios nos testes utilizados como parâmetro, frisamos também a dependência de concentração para o efeito apresentado, o que sugerimos estar relacionado com a seletividade para com os seus receptores. Concluiu-se que a ativação dos receptores de adenosina pode influenciar a proliferação de cardiomiócitos neonatais de rato, no entanto ressaltamos a necessidade de utilização de ensaios mais apurados para detecção de proliferação celular propriamente dita. 